Supporting Information

\title{
Monitoring Neuroinflammation with an HOCl-Activatable and Blood-Brain Barrier Permeable Upconversion Nanoprobe
}

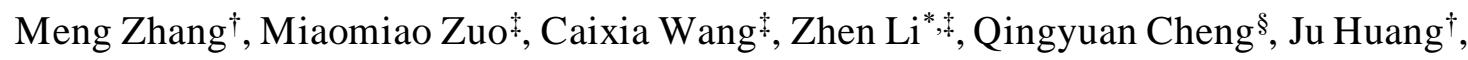
Zijun Wang ${ }^{\dagger}$, Zhihong Liu ${ }^{*}, \dagger$,

†College of Chemistry and Molecular Sciences, Wuhan University, Wuhan 430072, China

$¥$ Ministry of Education Key Laboratory for the Synthesis and Application of Organic Functional Molecules and College of Chemistry and Chemical Engineering, Hubei University, Wuhan 430062, China

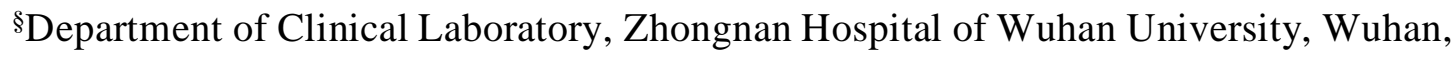
430071, China.

*Corresponding author: Zhen Li; Zhihong Liu

Email: zhenli@whu.edu.cn; zhhliu@whu.edu.cn 


\section{Table of Contents}

\section{Materials}

\section{Instrumentation}

Figure S1. XRD patterns of upconversion nanoparticles.

Figure S2-3. UV-vis absorption spectra of $\mathrm{Cy}-\mathrm{HOCl}$ before and after reacting with $\mathrm{HOCl}$.

Figure S4. The UCL intensities of ANG-UCNPs after incubation with HOCl.

Figure S5-6. Characterization of CyH-UCNPs.

Figure S7. UV-vis absorption spectra of CyH-UCNPs after reacting HOCl.

Figure S8. UCL change of $\mathrm{CyH}-\mathrm{UCNPs}$ after reaction with $\mathrm{HOCl}$ as the function of time.

Figure S9. Selectivity and stability of CyH-UCNPs.

Figure S10. Cell viability assay.

Figure S11. H\&E staining assays and blood biochemical analysis.

Figure S12. The biodistribution of CyH-UCNPs and UCNPs@PEG-CyHOCl.

Figure S13. The expression levels of inflammation-related protein MPO and proinflammatory cytokines IL-1 $\beta$.

Figure S14. In vivo UCL imaging of the mice in LPS-induced NI model.

Figure S15. The synthetic routine of $\mathrm{Cy}-\mathrm{HOCl}$.

Figure S16. Schematic illustration of the measurement of TEER value.

Figure S17-18. Characterization of of Cy-HOCl. 
Materials. 1-Octadecene, oleic acid and glutathione were purchased from Aladdin Reagent, Ltd. (Shanghai, China). Lipopolysaccharide and minocycline were purchased from Sigma-Aldrich. DSPE-PEG2000 was acquired from Ponsure biological Co., Ltd. (Shanghai, China). ANG-DSPE-PEG 2000 was obtained from Ruixi biological technology Co., Ltd. (Xi-an, China). Mouse IL-1 beta uncoated ELISA Kit was purchased from Thermo Fisher (USA). Mouse myeloperoxidase (MPO) ELISA Kit was obtained from NeoBiscience (USA). Other chemical reagents were purchased from Sinopharm Chemical Reagent Co., Ltd. (Shanghai, China). All the reagents were analytical or better grade and used without further purification. All aqueous solution was prepared with ultrapure water (Mill-Q, Millipore, $18.2 \mathrm{M} \Omega \cdot \mathrm{cm}$ resistivity). Mice were supplied by Wuhan Centers for Disease Prevention \& Control (Wuhan, China). All animal studies were performed in accordance with Animal Care and Use Committee of Wuhan University.

Instrumentation. The size and morphology of upconversion nanoparticles were characterized by the JEM-2010 transmission electron microscope (TEM) operated at $200 \mathrm{kV}$. XRD measurement was acquired by an X-ray diffractometer (XRD, Bruker D8 Discover) with a $2 \theta$ range of $10^{\circ}-80^{\circ}$ with $\mathrm{Cu} \mathrm{K} \alpha$ irradiation $(\mathrm{k}=1.5406 \AA)$. FT-IR spectra were conducted on Nicolet 5700 FTIR Spectrometer (Thermo Fisher Scientific, USA). UV-Vis spectra were measured by UV 2550 UV-Vis spectrophotometer (Shimadzu, Japan). The UCL spectra were recorded on RF-6000 fluorophotometer 
(Shimadzu, Japan) equipped with an external $980 \mathrm{~nm} \mathrm{CW}$ laser (Beijing Hi-Tech Optoelectronic Co., Ltd.). CCK8 test was conducted on Mk3 microplate reader (Thermo Scientific Multiskan, USA). In vivo UCL imaging was acquired by PerkinElmer IVIS Spectrum. Gd content in the major organs of mice was analyzed by ICP-MS (PlasmaQuant MS, German). Gd content in in vitro BBB model was analyzed by ICP-OES (Thermo IRIS Intrepid II, USA).

Preparation of HOCl. The HOCl solution was prepared by diluting the commercial sodium hypochlorite solution with ultrapure water. ${ }^{[1]}$ The concentration was determined by the UV-Vis absorbance at $292 \mathrm{~nm} .\left(\varepsilon=360 \mathrm{M}^{-1} \mathrm{~cm}^{-1}\right)$

Preparation of $\mathrm{OONO}^{-}$solution. The $\mathrm{OONO}^{-}$solution was obtained by mixing of sodium nitrite solution $(0.6 \mathrm{M}, 3 \mathrm{~mL})$, sodium hydroxide solution $(1.5 \mathrm{M}, 3 \mathrm{~mL})$ and hydrogen peroxide $(0.7 \mathrm{M}, 1.5 \mathrm{~mL})$ in hydrochloric acid $(0.6 \mathrm{M}, 1.5 \mathrm{~mL}){ }^{[2]}$ Furthermore, the concentration of the $\mathrm{OONO}^{-}$solution was determined by measuring the UV-vis absorbance at $302 \mathrm{~nm}$ in $0.1 \mathrm{M} \mathrm{NaOH} .\left(\varepsilon=1670 \mathrm{M}^{-1} \mathrm{~cm}^{-1}\right)$

Preparation of $\mathrm{O}_{2}{ }^{--}$solution. Potassium superoxide $\left(\mathrm{KO}_{2}\right)$ was dissolved in DMSO under the condition of ultrasonication. ${ }^{[2]}$ The concentration of $\mathrm{O}_{2}{ }^{--}$was determined by measuring the UV-vis absorbance at $256 \mathrm{~nm}$ in $1 \mathrm{mM} \mathrm{NaOH} .\left(\varepsilon=2686 \mathrm{M}^{-1} \mathrm{~cm}^{-1}\right)$

Preparation of $\bullet \mathbf{O H} \cdot \cdot \mathrm{OH}$ was prepared by fenton reaction between Iron(II) sulfate ( $\mathrm{FeSO}_{4}$ ) and hydrogen peroxide $\left(\mathrm{H}_{2} \mathrm{O}_{2}\right) \cdot{ }^{[2]}$ Generally, $\mathrm{FeSO}_{4}$ and $\mathrm{H}_{2} \mathrm{O}_{2}$ was respectively dissolved in dilute sulphuric acid with the final concentration of $0.1 \mathrm{mM}$ and mixed them with the concentration ratio of 1:6. 


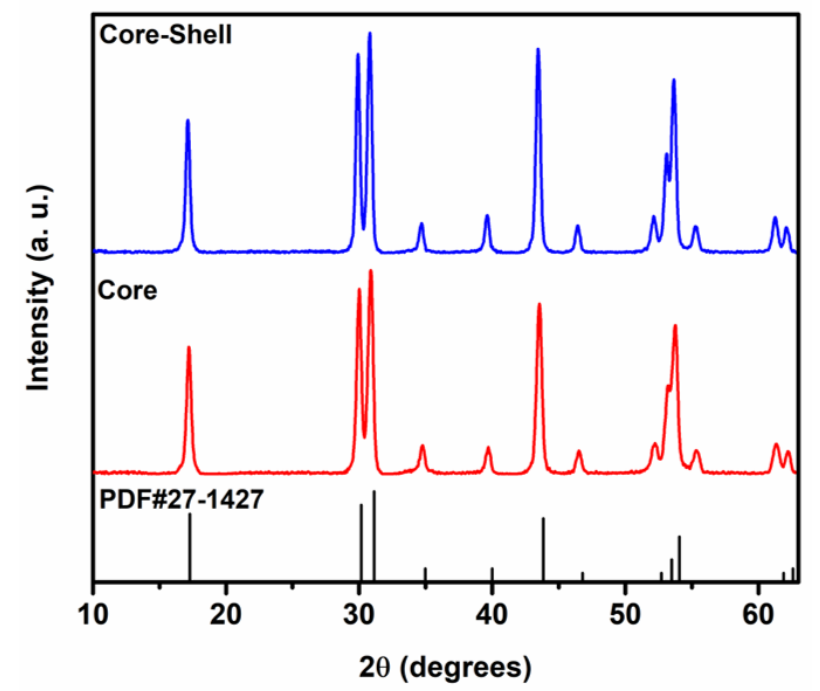

Figure S1. XRD patterns of the core nanoparticles $\mathrm{NaYbF}_{4}: 0.25 \mathrm{Gd}$, core-shell nanoparticles NaYbF4:0.25Gd@NaYF4:0.04Yb,0.015Tm, and the standard hexagonal $\mathrm{NaYbF}_{4}$ crystal (Joint Committee on Powder Diffraction Standards file number 27 1427).

A

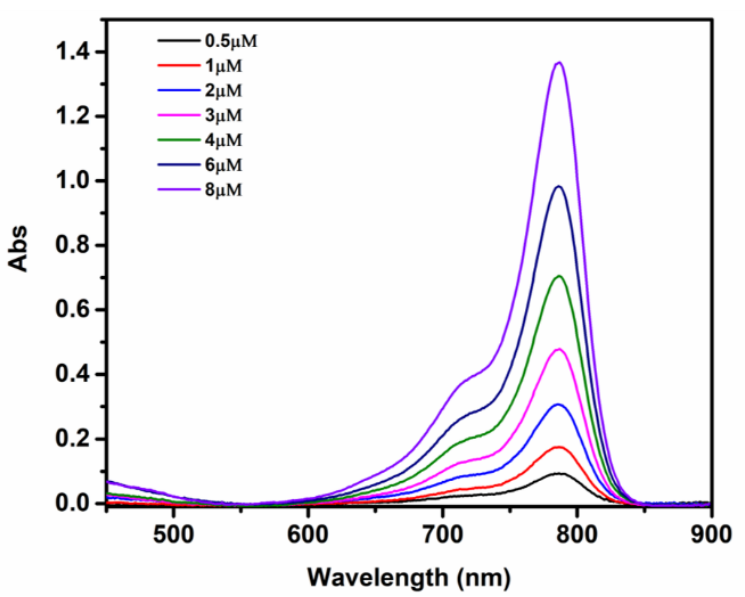

B

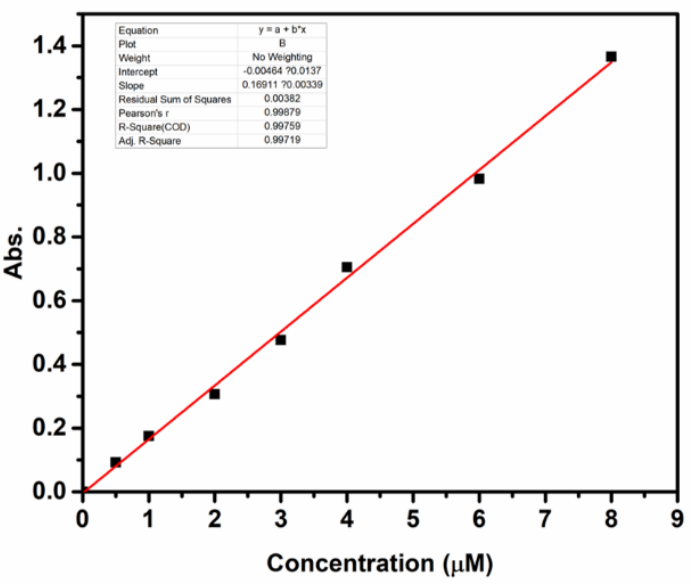

Figure S2. (A) UV-vis absorption spectra of Cy-HOCI in DMSO. (B) Linear relationship between UV-vis absorbance and the concentration of $\mathbf{C y}-\mathbf{H O C l}$ at $786 \mathrm{~nm}$. 


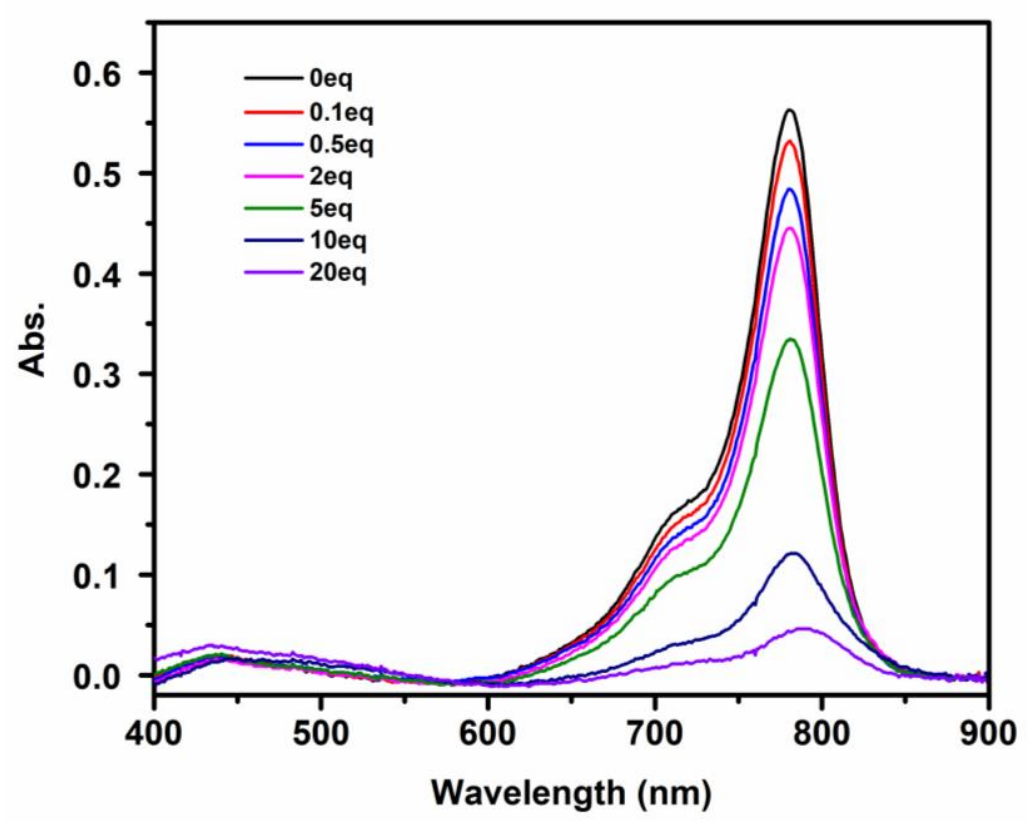

Figure S3. UV-vis absorption spectra of $10 \mu \mathrm{M} \mathrm{Cy}-\mathbf{H O C l}$ after reacting with different equivalents of $\mathrm{HOCl}$ in the mixture solvent of DMF and boric acid buffer (v:v=1:1, $\mathrm{pH}=7.4,20 \mathrm{mM})$.

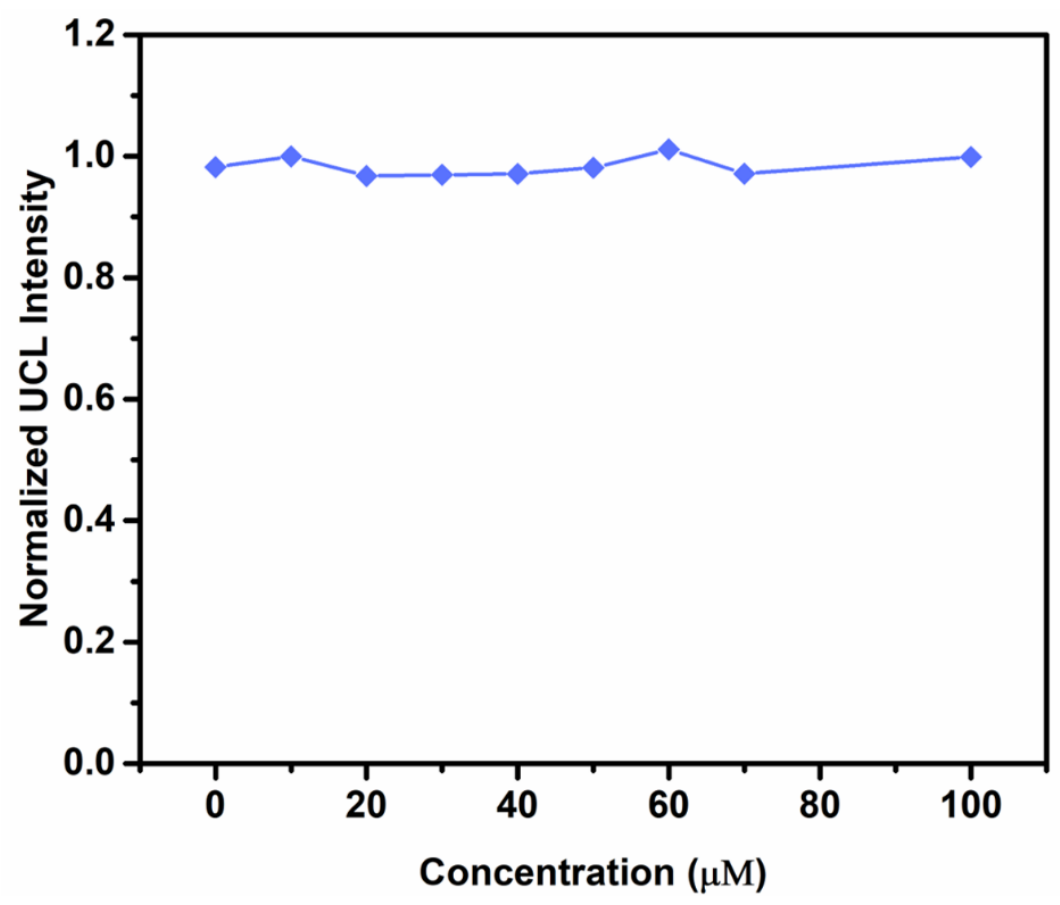

Figure S4. The UCL intensities of ANG-UCNPs after incubation with different concentrations of $\mathrm{HOCl}$ at $37{ }^{\circ} \mathrm{C}$ for $1 \mathrm{~h}$ in boric acid buffer $(\mathrm{pH}=7.4,20 \mathrm{mM})$. 
A
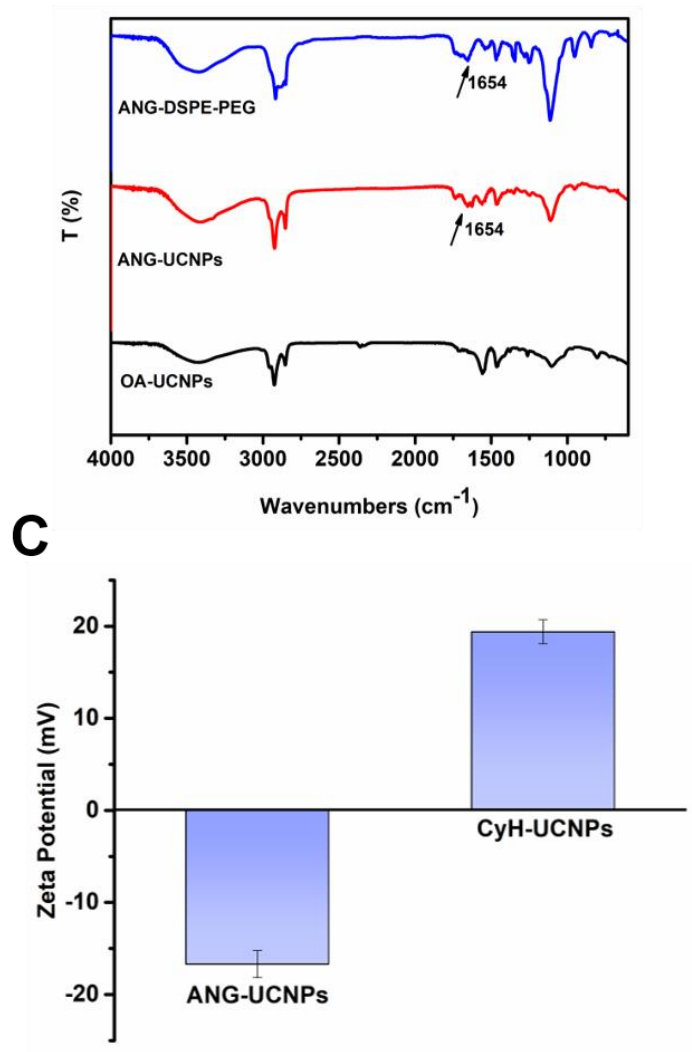

B
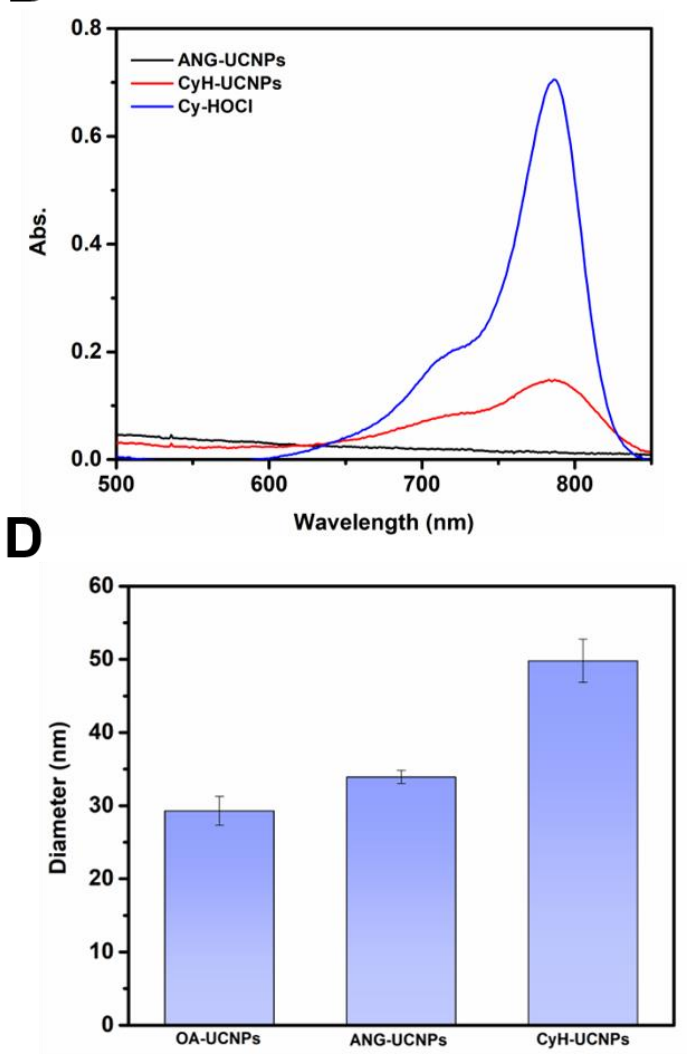

Figure S5. (A) FTIR spectra of OA-UCNPs, ANG-UCNPs, and ANG-DSPE-PEG. (B) UV-vis absorption spectra of $\mathbf{C y - H O C l , ~ C y H - U C N P s , ~ a n d ~ A N G - U C N P s . ~ ( C ) ~ Z e t a ~}$ potentials of ANG-UCNPs and CyH-UCNPs. (D) The change of diameter of OA-UNPs, ANG-UCNPs, and CyH-UCNPs (note: the diameter of OA-UNPs was acquired by TEM images, the diameter of ANG-UCNPs and CyH-UCNPs were measured by DLS). 


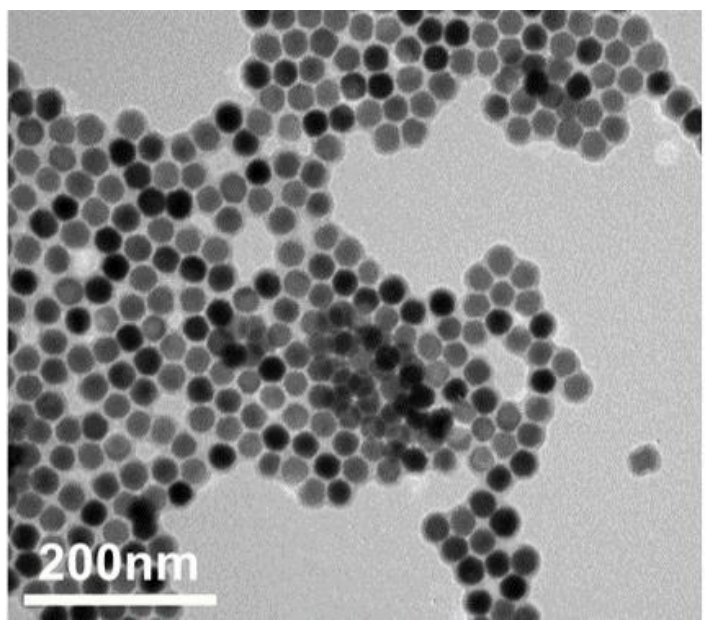

Figure S6. TEM image of CyH-UCNPs.

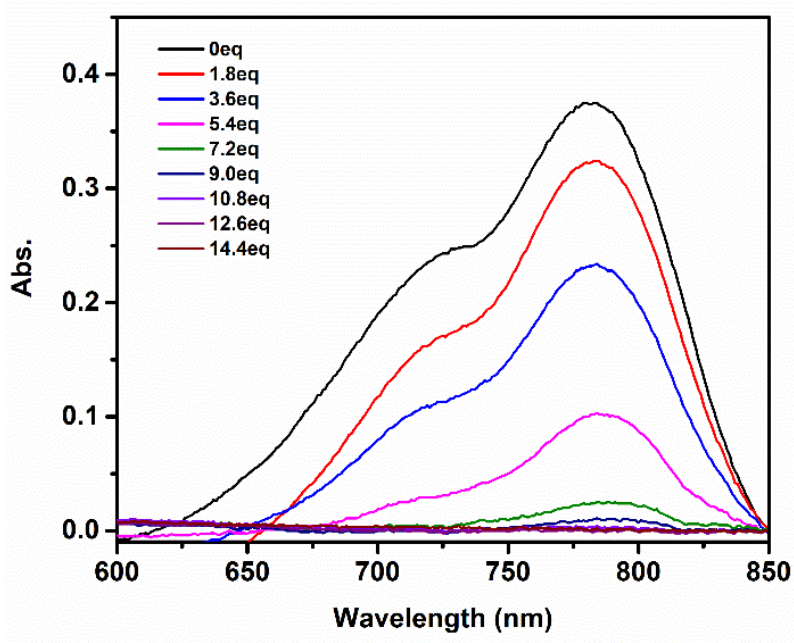

Figure S7. UV-vis absorption spectra of $2.17 \mu \mathrm{M} \mathrm{Cy-HOCl}$ assembled on the UCNPs after reacting with different equivalents of $\mathrm{HOCl}$ in boric acid buffer $(\mathrm{pH}=7.4,20 \mathrm{mM})$. 


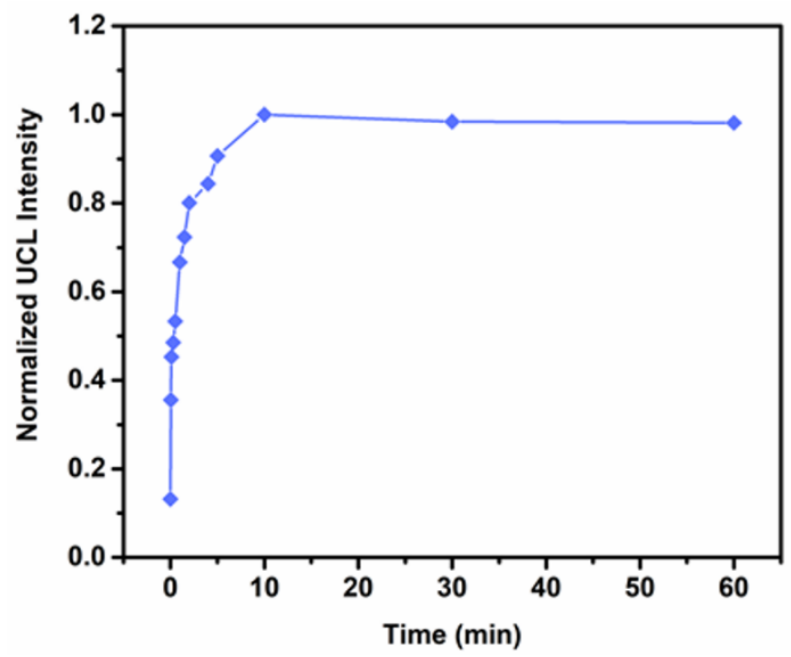

Figure S8. Dependence of the UCL intensity at $800 \mathrm{~nm}$ of CyH-UCNPs on the time of reaction with $10 \mu \mathrm{M} \mathrm{HOCl}$ at $37^{\circ} \mathrm{C}$ in boric acid buffer $(\mathrm{pH}=7.4,20 \mathrm{mM})$.

A

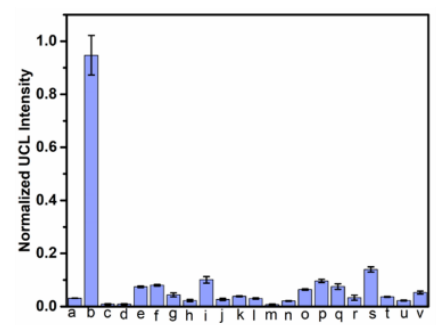

B

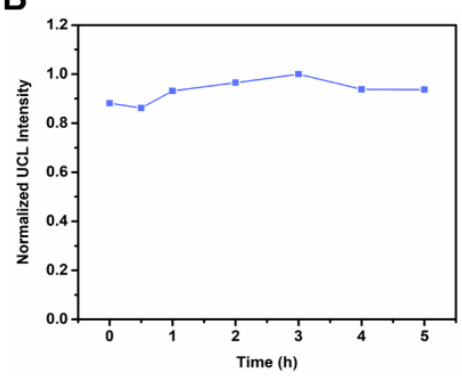

C

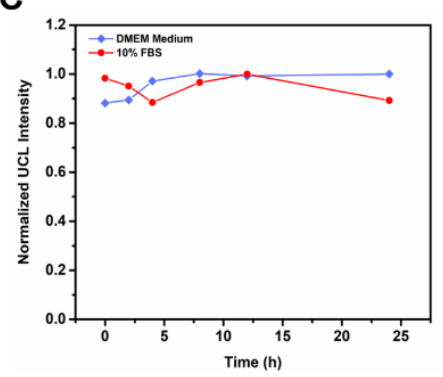

Figure S9. (A) Response of CyH-UCNPs to the potential interferents and HOCl. (a: blank, b: $20 \mu \mathrm{M} \mathrm{HOCl}, \mathrm{c}, \mathrm{d}: \mathrm{Cu}^{2+}, \mathrm{Fe}^{3+}(200 \mu \mathrm{M})$, e-i: $\mathrm{Ca}^{2+}, \mathrm{Mn}^{2+}, \mathrm{Li}^{3+}, \mathrm{Mg}^{2+}, \mathrm{Zn}^{2+}(1$ $\mathrm{mM})$, j,k: $\mathrm{K}^{+}, \mathrm{Na}^{+}(10 \mathrm{mM})$, l-q: Hcy, Lys, His, $\mathrm{Na}_{2} \mathrm{~S}, \mathrm{GSH}, \mathrm{H}_{2} \mathrm{O}_{2}(1 \mathrm{mM}), \mathrm{r}^{-} \mathrm{O}_{2}-{ }^{--}(200$ $\mu \mathrm{M})$, s,t: $\mathrm{ONOO}^{-}, \cdot \mathrm{OH}(100 \mu \mathrm{M})$, u: BSA $(0.1 \mathrm{mg} / \mathrm{mL})$, v: glucose $\left.(1 \mathrm{mM})\right)$. (B) Thermal stability of CyH-UCNPs $(0.05 \mathrm{mg} / \mathrm{mL})$ in boric acid buffer $(\mathrm{pH}=7.4,20 \mathrm{mM})$ at $37^{\circ} \mathrm{C}$. (C) Stability of CyH-UCNPs $(0.05 \mathrm{mg} / \mathrm{mL})$ in the different media at $37^{\circ} \mathrm{C}$. 
A

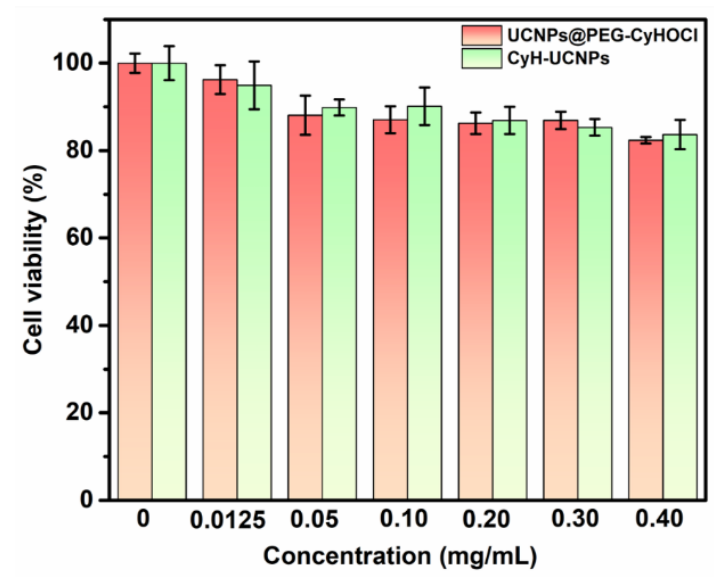

B

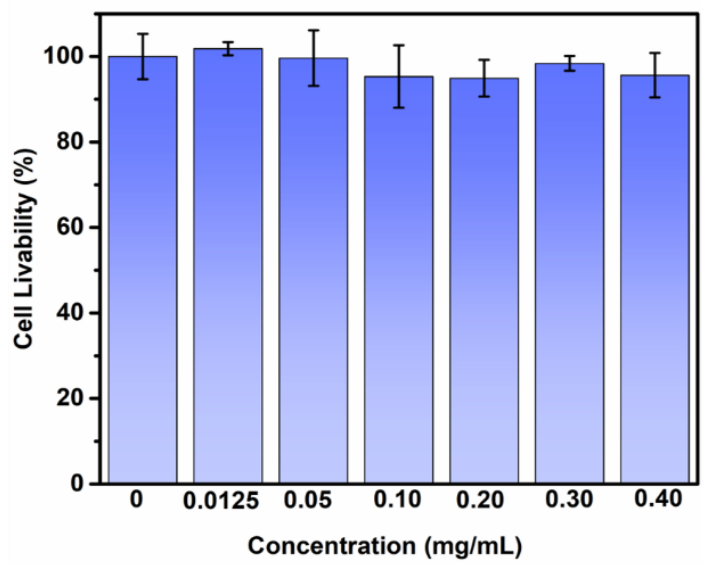

Figure S10. (A) The viability of human brain microvascular endothelial cell after incubation with different concentrations of CyH-UCNPs and UCNPs@PEG-CyHOCl for $24 \mathrm{~h}$. (B) The viability of PC12 cell after incubation with different concentrations of CyH-UCNPs for $24 \mathrm{~h}$.

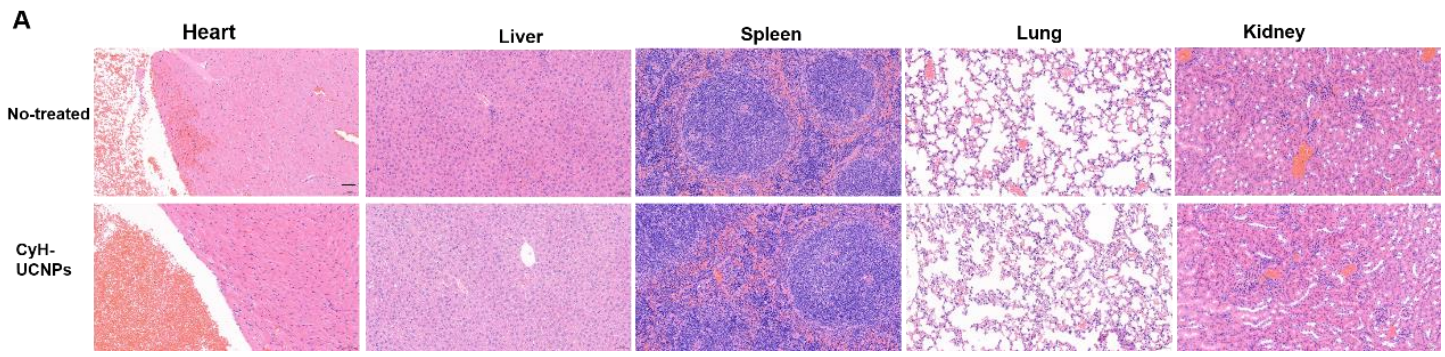

B
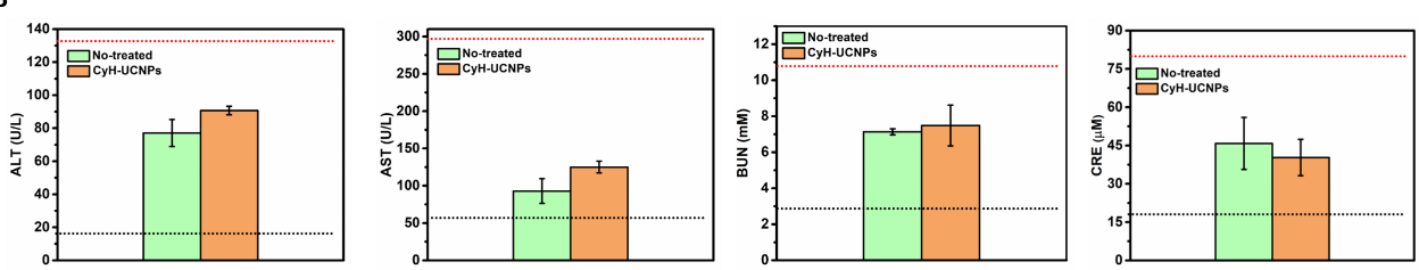

Figure S11. (A) H\&E staining assays of the mice major organs with or without $\mathrm{CyH}$ UCNPs treatment for 7 days. Scale bar: $50 \mu \mathrm{m}$. (B) Blood biochemical analysis of the mice with or without CyH-UCNPs treatment for 7 days. The red and black lines represent the highest and lowest reference value of alanine aminotransferase (ALT), aspartate aminotransferase (AST), blood urea nitrogen (BUN) and creatinine (CRE), respectively. ${ }^{[3]}$ 
A

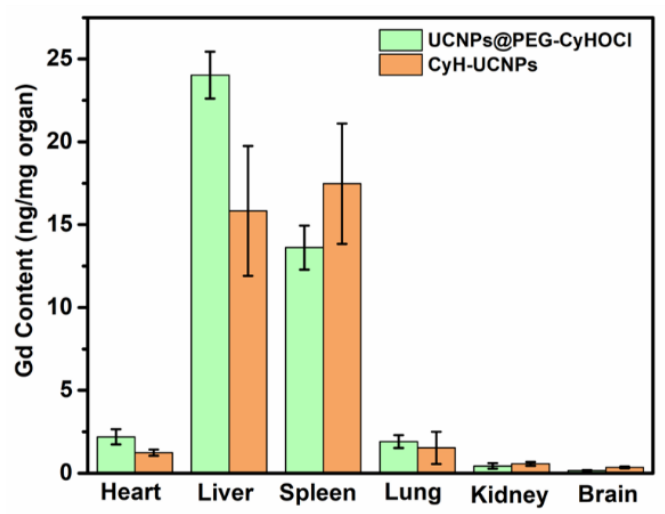

B

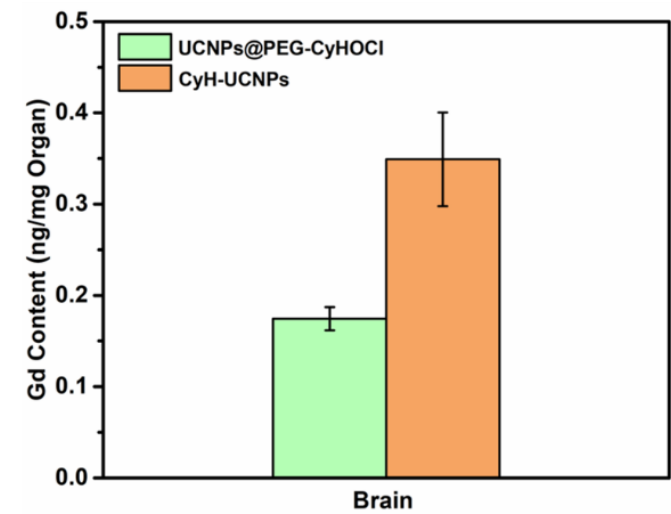

Figure S12. (A) The biodistribution of CyH-UCNPs and UCNPs@PEG-CyHOCl in the major organs of healthy mice after i.v. injection for $4 \mathrm{~h}$ by analyzing $\mathrm{Gd}$ content using ICP-MS. (B) The biodistributions of UCNPs@PEG-CyHOCl and CyH-UCNPs in the brain of healthy mice after i.v. injection for $4 \mathrm{~h}$ by analyzing $\mathrm{Gd}$ content using ICP-MS.

A

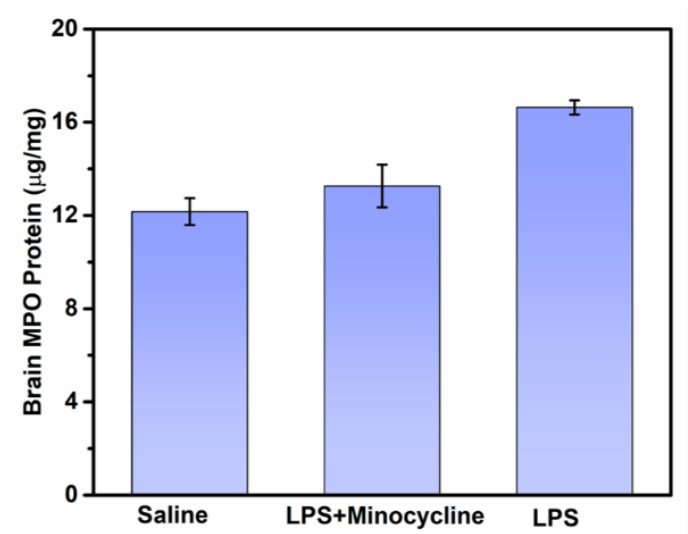

B

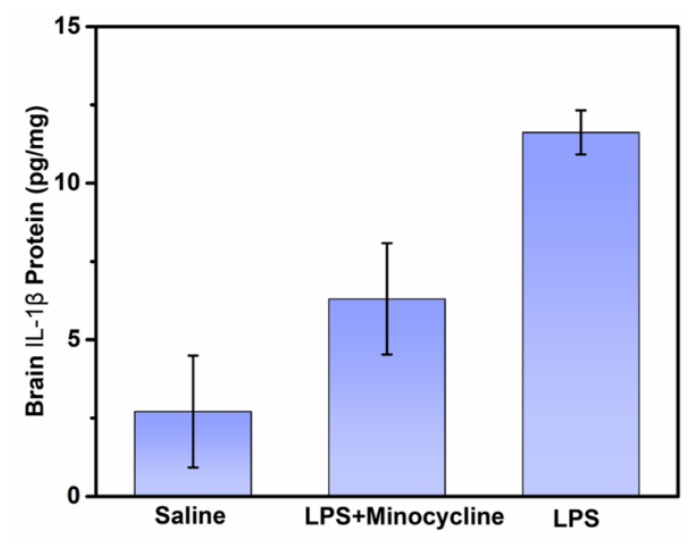

Figure S13. The expression levels of inflammation-related protein MPO (A) and proinflammatory cytokines IL-1 $\beta$ (B) in the brain tissue of the mice with different treatments. 
A

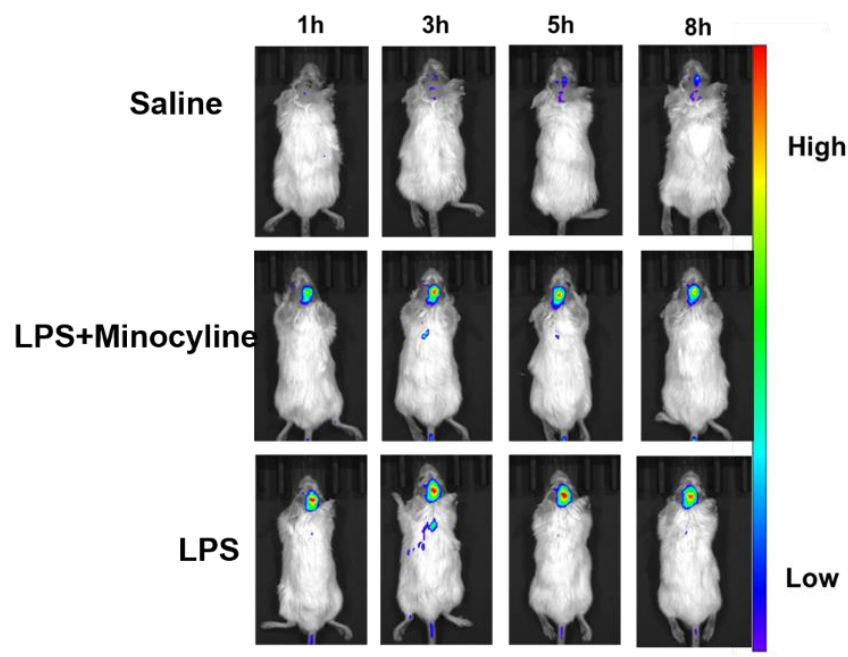

B

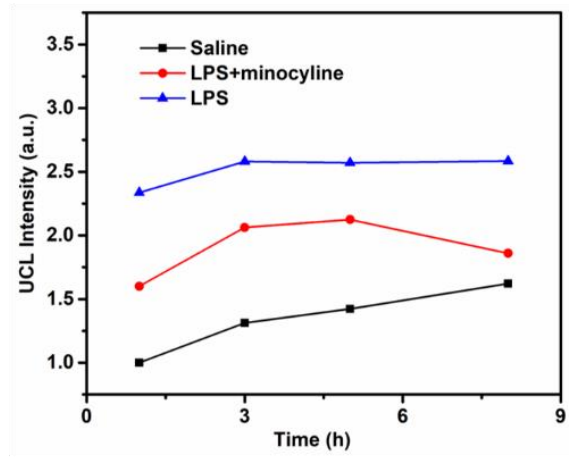

Figure S14. (A) In vivo UCL imaging of the mice with different treatments at 1, 3, 5, and $8 \mathrm{~h}$ after intravenous injection with CyH-UCNPs. (B) UCL intensities in images (A).

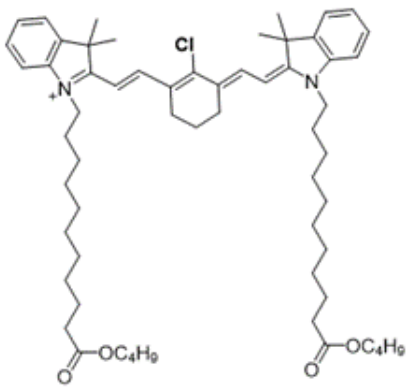

1

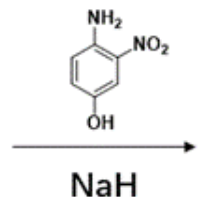

Figure S15. Synthetic routine of Cy-HOCl.

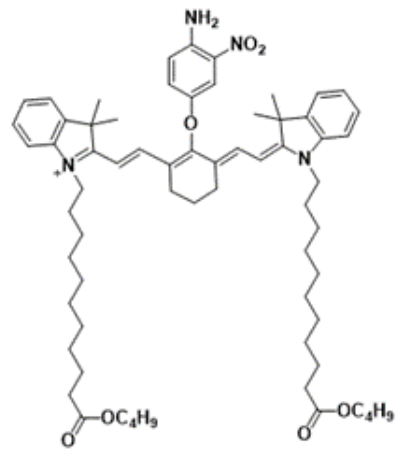

Cy- $\mathrm{HOCl}$ 


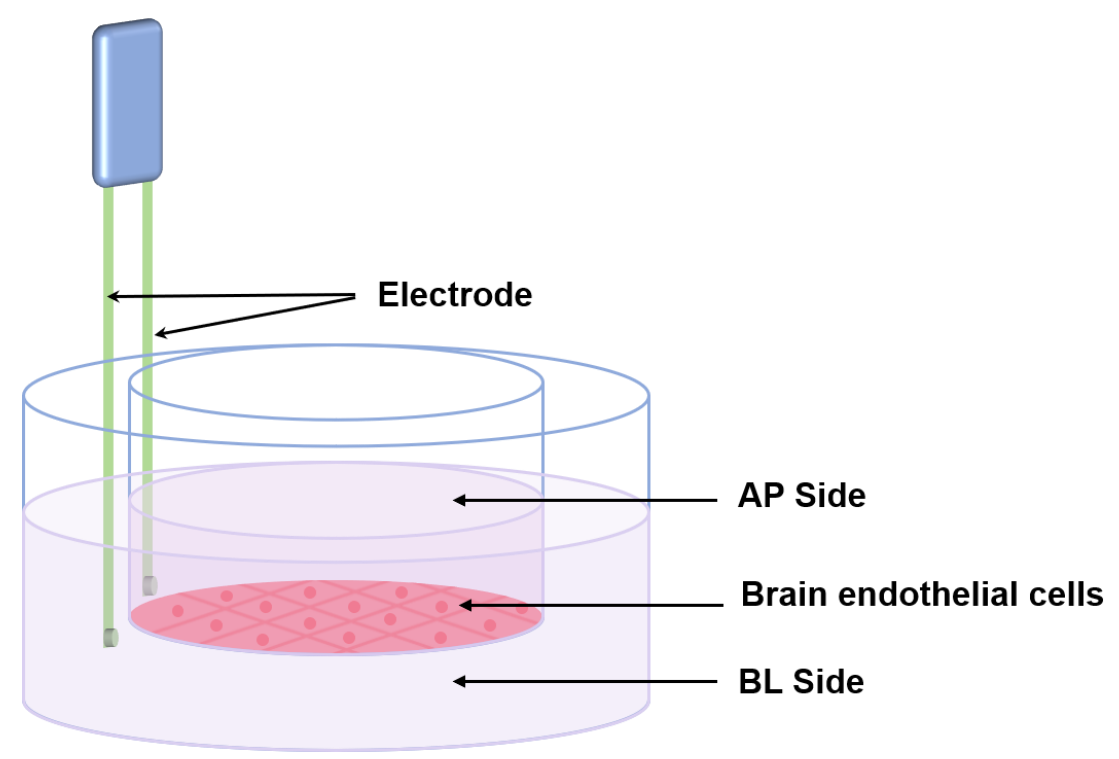

Figure S16. Schematic illustration of the measurement of TEER value.

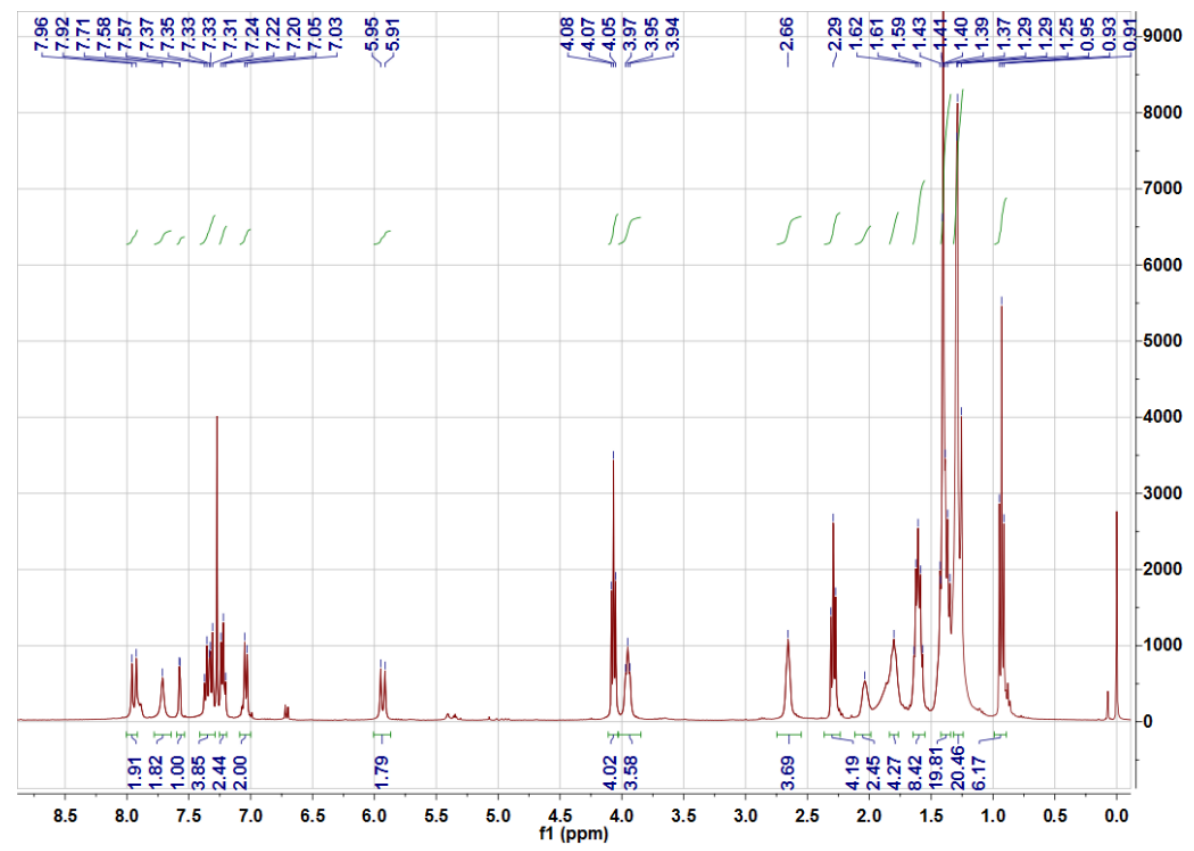

Figure S17. ${ }^{1} \mathrm{H}$ NMR spectrum of $\mathbf{C y}-\mathbf{H O C l}$. 


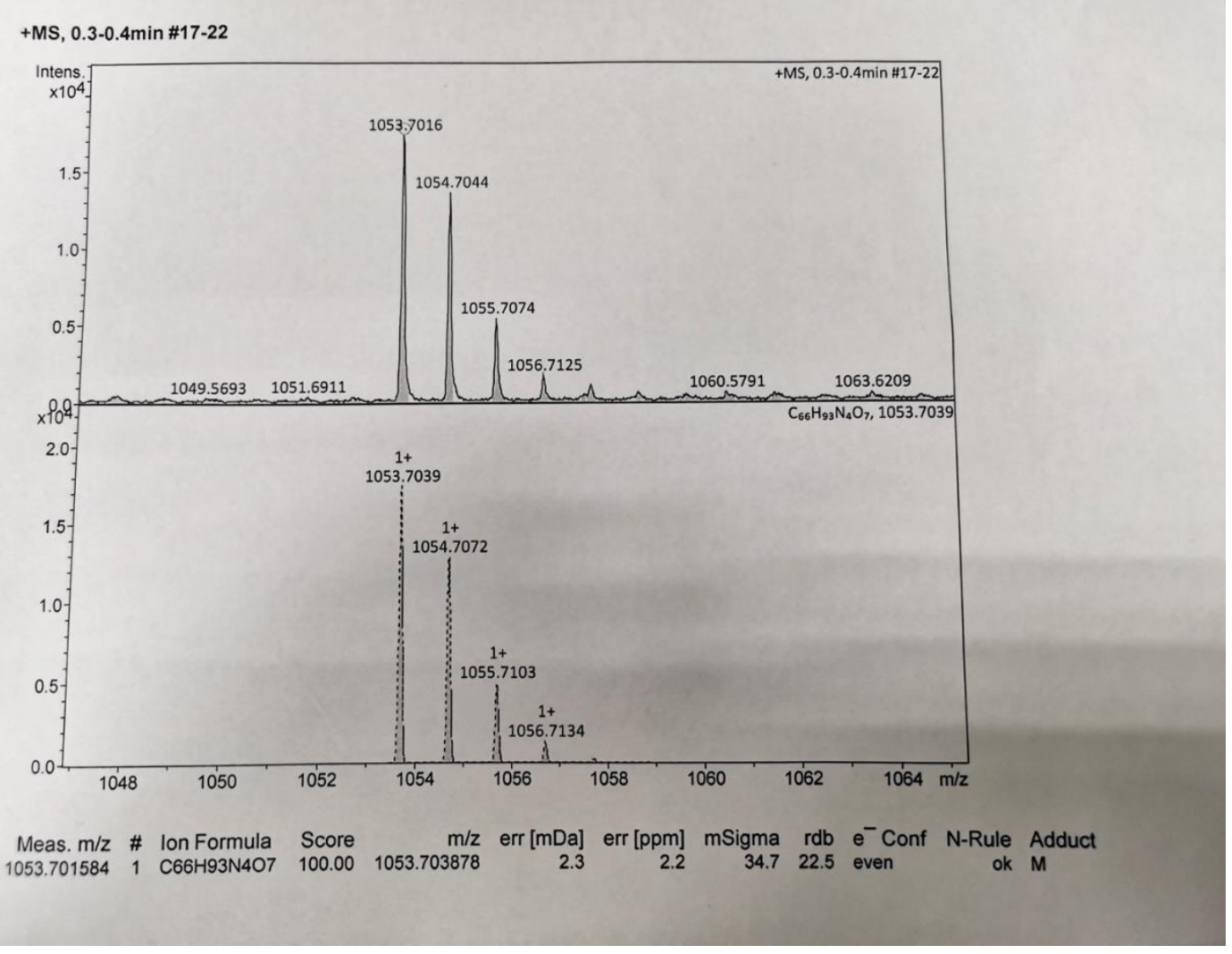

Figure S18. High resolution mass spectrum (HRMS) of Cy-HOCI.

\section{Reference}

[1] Zeng, L.; Xia, T.; Hu, W.; Chen, S.; Chi, S.; Lei, Y.; Liu, Z. Anal. Chem. 2018, 90, $1317-1324$.

[2] Ai, X.; Wang, Z.; Cheong, H.; Wang, Y.; Zhang, R.; Lin, J.; Zheng, Y.; Gao, M.; Xing, B. Nat. Commun. 2019, 10, 1087.

[3] Gong, N.; Ma, X.; Ye, X.; Zhou, Q.; Chen, X.; Tan, X. Nat. Nanotech. 2019, 14, $379-387$. 